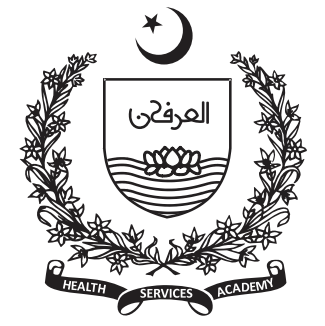

${ }^{1}$ Assistant Professor \& Head, Department of Oral Biology, Altamash Institute of Dental Medicine, Karachi, Pakistan. ${ }^{2}$ Assistant Professor \& Head, Department of Community Dentistry, Altamash Institute of Dental Medicine, Karachi, Pakistan

${ }^{3}$ Assistant Professor \& Head, Department of Orthodontics, Baqai Medical University, Karachi, Pakistan.

${ }^{4}$ Associate Professor \& Head, Department of Oral and Maxillofacial Surgery, Altamash Institute of Dental Medicine, Karachi, Pakistan. 5Senior Lecturer, Department of Community Dentistry, Altamash Institute of Dental Medicine, Karachi, Pakistan. ${ }^{5}$ Lecturer, Department of Oral Biology, Altamash Institute of Dental Medicine, Karachi, Pakistan.

Corresponding Author:

Muhammad Mansoor Majeed Email:

mmansoormajeed@gmail.com

\section{Oral Health Status and Treatment Needs of Police Personnel in Karachi}

\author{
Muhammad Mansoor Majeed 1*, Naseer Ahmed 2, Muhammad Uzair ${ }^{3}$ \\ Dinaz Ghandhi ${ }^{4}$, Thelma Farast Bashir ${ }^{5}$, Zunaira Khalid ${ }^{6}$
}

\section{Abstract}

Background: Oral health is an integral part of general health. Loss of teeth reduces the quality of life. Periodontal diseases constitute the major cause of tooth extraction in adults. A high prevalence of periodontal diseases among adults with considerable disparities between populations has been reported. Many studies have been reported in the literature depicting the periodontal status and treatment needs of different populations. This study aimed to assess the oral health status and treatment needs of police personnel in Sindh Police, Pakistan.

Methods: In this cross-sectional study, 174 police personnel from the Special Security Unit (SSU) of Sindh Police in Karachi were examined clinically and evaluated using the WHO 2013 Oral Health Assessment Form. Consent was obtained from the concerned authorities.

Results: - The study showed that $43.1 \%(n=75)$ periodontal status as healthy, $35 \%(n=61)$ reported gingivitis and periodontitis and $21.8 \%(n=38)$ reported moderate to severe periodontitis. The significant difference found in the periodontal health among males $\left(X^{2}=71.18, P<0.001\right)$ and females $\left(X^{2}=9.90\right.$, $\mathrm{P}<0.009$ ). More than $83.3 \%$ were suffering from Dental caries. The majority of the examined participants needed prompt treatment which included scaling and tooth restorations

Conclusion: Periodontal and oral health status among the police personnel was noted to be most compromised and there is an immense need to conduct oral health awareness sessions as a mandatory part not only in their training period but should be employed in their daily routine.

Keywords: Dentistry; security personnel; occupational health

\section{Introduction}

$\mathrm{H}$ ealth is a state of complete physical, mental, and social well-being and not merely an absence of a disease or infirmity (1). The mouth is considered a mirror of the body (2). Oral wellbeing and general wellbeing are administered by different factors, for example, way of life, dietary propensities, financial conditions, workrelated conditions, etc. Oral wellbeing implies more than sound teeth. Oral wellbeing empowers a person to talk, eat, and associate without the dynamic disease, distress, or shame. Oral wellbeing adds to individual well-being and personal satisfaction. General 
wellbeing and a healthy lifestyle are important for a healthy oral cavity. Oral diseases affect every person belonging to different ages and genders around the globe. For all intents and purposes, no person over the span of their lifetime escapes from dental diseases. (3) Work-related conditions assume a noteworthy job on the wellbeing of the people who are affected. The wellbeing risks get increasingly serious with the trouble of job policing is a mind-boggling occupation. As there is a wide scope of exercises associated with police work, numerous wellbeing, and security issues encompass policing as an occupation. $(4,5)$

Policing is a difficult profession and has been categorized among the top stressful occupations since ages (6). The region that is involved by the law enforcement agency in a state is like a region involved by the armed forces in a country.

Studies also recorded that due to stress and pressure, police personnel suffer from various disorders including

stomach disorders, persistent insomnia, psychiatric dis orders, cardiovascular problems, family issues etc (7, 8 ). Due to the demand for this profession and involvement in different activities, there are many health and safety issue and psychological stress among the police personnel is relatively higher (9). Multiple studies have identified the role of stress in the deterioration of periodontal conditions (10).

In the past, multiple studies have been conducted to access the oral health of people from different fields of life, e.g. doctors, teachers, students, however, no information on the oral health status among the police staff of Karachi city is accessible. Though, a study was conducted to check the periodontal status in army personnel and reported that $32 \%$ are suffering from chronic periodontitis(11). Therefore, it is very crucial to address dental and periodontal problems and encourage good oral health of police personnel.

In a study conducted in Karachi to access the oral health status of the general population reported that that the prevalence of dental caries and periodontal disease is high along with other oral diseases and people have given this issue at least priority (12). Similarly, other studies conducted in different parts of Pakistan showed that periodontitis, gingivitis and dental caries are highly prevalent. In Path finder's survey of the World Health Organization that was conducted in 2003 indicated that DMFT (Decayed, Missing and Filled Teeth) score 8.73 in 35-45 years old age group and 18.39 in more than 65 years old people (13).

Consequently, this study was performed to analyze the oral and dental problems among the police personnel of Special Security Unit of Sindh Police and their treatment needs to protect the oral and systemic health of the guardians of the city. This study will set a benchmark for setting goals and determining the preventive measures and treatment required for the police personnel.

\section{Methodology}

This cross-sectional observational study was performed in Karachi in August 2019. Uniformed police personnel from the Special Security Unit of Sindh Police were the participants. We followed the convenience sampling technique and all those police personnel who were present on the examination day were recruited in the current study. Participants were clinically examined using the World Health Organization (WHO) 2013 Oral Health Assessment Form (14). The average time for the examination and data collection was 10 minutes for each subject. Clinical examinations were performed by trained examiners and house officers under the supervision of the principal investigator and senior faculty members of the dental institutes. The examination was conducted at the premises of SSU under natural light and the instruments utilized were dental mirrors, tongue depressors, and periodontal probes. Ethical permission was given by the ethics and review committee of the Altamash Institute of Dental Medicine. SPSS 21 was used for data entry and data analysis.

\section{Results}

Data of 174 police respondents analyzed, males constituted $75.9 \%(n=132)$ and females $24.1 \%(n=42)$. The participants were divided into four (4) age groups; the majority $(n=71)$ were aged between 20-30 years, $(n=58)$ were between 31-40 years, $(n=29)$ between 41 50 years and $(n=16)$ were above 50 years respectively (Table 1).

It was observed that among the 174 participants, the periodontal status of $43.1 \%(n=75)$ was found to be healthy. Gingivitis was observed in $35.1 \%(n=61)$ and $21.8 \%(n=38)$ of the staff had periodontitis. As per the Mann-Whitney test, no significant difference was observed among the genders $(p>0.05)$. There was a 
significant relationship between age and periodontal health in both genders. It was observed that males of age group 20-30 years and 31-40 years had healthy gingiva and fewer had periodontitis whereas, males with an age group of $42-50$ and above 50 years of age suffered from moderate to severe periodontitis. $(\mathrm{p}<0.001)$ (Table 2).

Among the total participants, a significant number of individuals reported dental caries in 1 or more teeth. It was explored that 112 males and 33 females needed dental fillings in one or more teeth. Furthermore, 16 males and 22 females already had dental fillings. It was also observed that 42 males and 9 females had one or more missing teeth and needed dental prosthesis. On the other hand, 1 female and 14 males were using either removable or fixed dental prostheses (Table 3). We observed that $110(63.2 \%)$ were using toothpaste, $31(17.8 \%)$ miswak, $18(10.3 \%)$ tooth powder, and 15 $(8.6 \%)$ were using "manjan". It was also observed that $70(40.2 \%)$ of the individuals brushed once daily, 81 (47) brush twice a day and 23 (13.2\%) police personnel cleaned their teeth 3 or more times a day (Figure 1). We explored that $35(20.1 \%)$ of the subjects rinse their mouth with water or any mouth wash after every meal, 67 (38.5\%) often followed this practice and 66 $(37.9 \%)$ rinse their mouth occasionally and $7(4 \%)$ do not rinse their mouth after a meal. (Table 1)

Table 1: Demographics and Oral Hygiene Practices

\begin{tabular}{|c|c|c|c|c|c|}
\hline Gender & $\mathbf{2 0 - 3 0}$ & $\mathbf{3 1 - 4 0}$ & $\mathbf{4 1 - 5 0}$ & $\mathbf{5 0 +}$ & Total \\
\hline Male & $43(32.6 \%)$ & $44(33.3 \%)$ & $29(22.0 \%)$ & $16(12.1 \%)$ & $132(75.9 \%)$ \\
\hline Female & $28(66.7 \%)$ & $14(33.3 \%)$ & $0(.0 \%)$ & $0(.0 \%)$ & $42(24.1 \%)$ \\
\hline Total & $71(40.8 \%)$ & $58(33.3 \%)$ & $29(16.7 \%)$ & $16(9.2 \%)$ & 174 \\
\hline $\begin{array}{c}\text { Tooth } \\
\text { Paste }\end{array}$ & 41 & 40 & 19 & 10 & 110 \\
\hline $\begin{array}{c}\text { Tooth } \\
\text { Powder }\end{array}$ & 10 & 0 & 4 & 4 & 18 \\
\hline Miswak & 11 & 14 & 4 & 2 & 31 \\
\hline Manjan & 9 & 4 & 2 & 0 & 15 \\
\hline Never & 2 & 2 & 1 & 2 & 7 \\
\hline Rarely & 8 & 11 & 8 & 2 & 29 \\
\hline $\begin{array}{c}\text { Some } \\
\text { Times }\end{array}$ & 11 & 13 & 8 & 6 & 38 \\
\hline Often & 32 & 24 & 7 & 2 & 65 \\
\hline Always & 18 & 8 & 5 & 4 & 35 \\
\hline
\end{tabular}

We evaluated that only $15.54(\mathrm{n}=27)$ police personnel do not need any dental treatment and $84.48 \%(n=147)$ require preventive or routine dental treatment. More than half needs prosthesis and the majority needs filling or root canal treatments (Figure 2).

It was revealed that $36(20.7 \%)$ of the police personnel never visited dentists, $80(46.00 \%)$ out of 174 visited dentists in the last 10 years, in the last five years, 37 $(21.3 \%)$ visited the dentist and only $21(12.1 \%)$ visited the dentist in the last year. Among the 138 police personnel who visited the dentist due to some oral and dental issues were $112(81.15 \%)$ and only 26 (18.84\%) went for a general checkup (Figure 3).

Table 2: Relationship of Age with Periodontal Status in both genders

\begin{tabular}{|c|c|c|c|c|c|c|c|c|}
\hline \multirow[b]{2}{*}{ Gender } & \multirow[b]{2}{*}{ Status } & \multicolumn{4}{|c|}{ Age Group } & \multirow[b]{2}{*}{ Total } & \multirow[b]{2}{*}{$X^{2}$} & \multirow{2}{*}{$\begin{array}{c}\text { P- } \\
\text { Value }\end{array}$} \\
\hline & & $\begin{array}{c}20- \\
30\end{array}$ & \begin{tabular}{|c|}
$31-$ \\
40
\end{tabular} & $\begin{array}{l}41- \\
50\end{array}$ & $50+$ & & & \\
\hline \multirow{3}{*}{ Males } & Healthy & 27 & 20 & 6 & 2 & 55 & \multirow{4}{*}{71.18} & \multirow{4}{*}{$\begin{array}{c}< \\
0.001\end{array}$} \\
\hline & Gingivitis & 15 & 22 & 8 & 0 & 45 & & \\
\hline & Periodontitis & 1 & 2 & 15 & 14 & 32 & & \\
\hline \multicolumn{2}{|l|}{ Total } & 43 & 44 & 29 & 16 & 132 & & \\
\hline \multirow{3}{*}{ Female } & Healthy & 18 & 2 & & & 20 & \multirow{4}{*}{9.90} & \multirow{4}{*}{0.007} \\
\hline & Gingivitis & 8 & 8 & & & 16 & & \\
\hline & Periodontitis & 2 & 4 & & & 6 & & \\
\hline Total & & 28 & 14 & & & 42 & & \\
\hline
\end{tabular}

Table 3: Distribution of Intraoral Status according to the gender

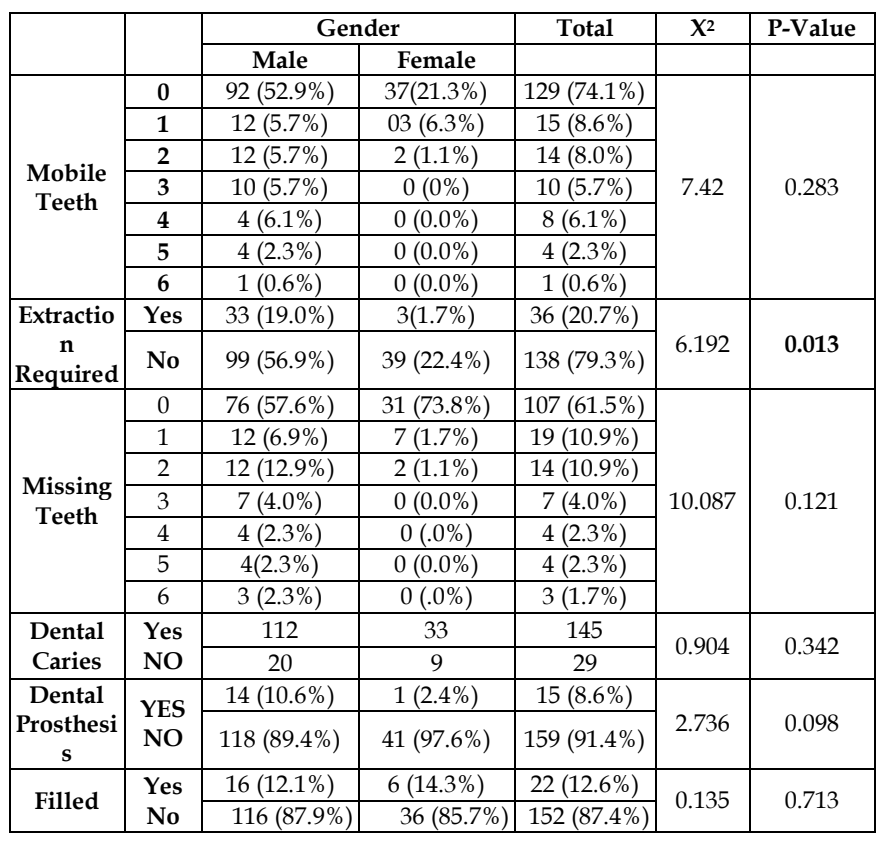




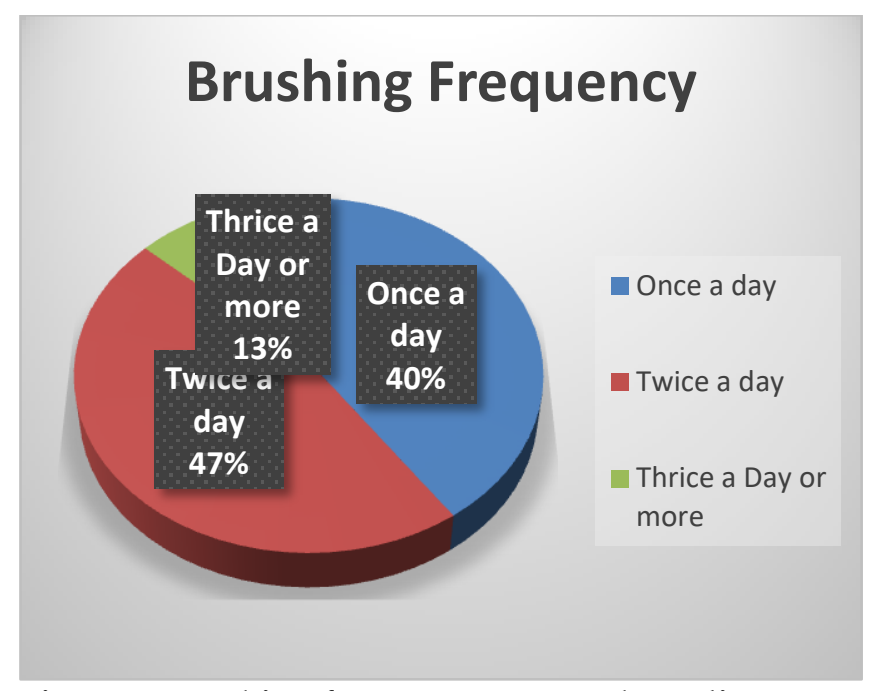

Figure 1: Brushing frequency among the Police Personnel

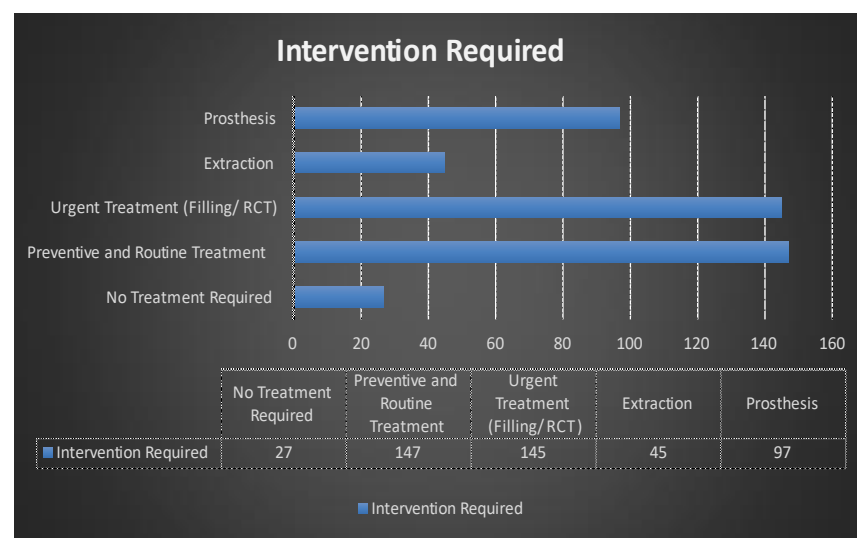

Figure 2: Intervention/ Treatment required

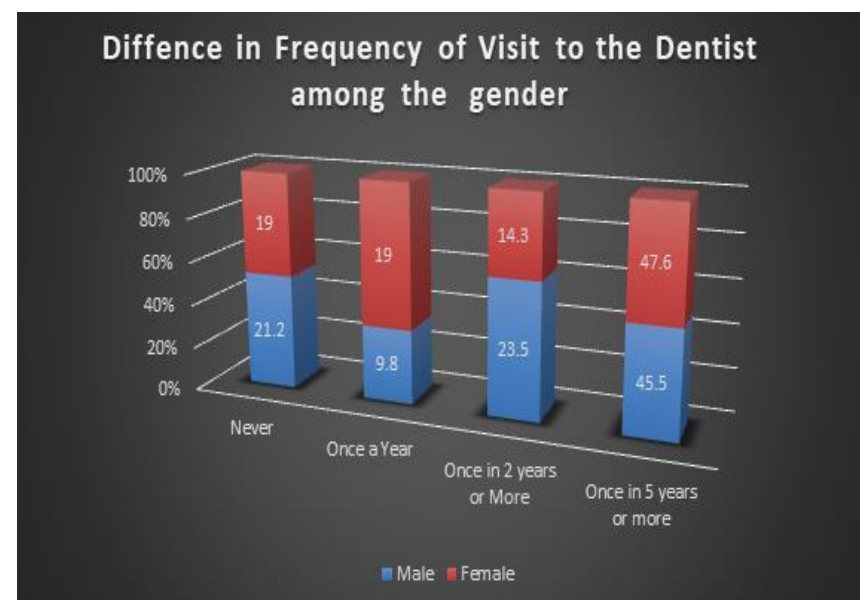

Figure 3: Frequency of visit to the dentist among males and female.

\section{Discussion}

This study aimed to investigate the periodontal status among the Special Service Unit of Sindh Police, Karachi along with their treatment needs. Previous literature reviews have revealed that many studies have been performed to check the dental and oral hygiene status of police personnel in other parts of the world despite this, however, no study to the best of our knowledge has been conducted so far to access the oral health status of police personnel in Pakistan.

In this study, the selected total of 174 police personnel were those who were present at the time of the visit. The mean age was found to be 34.62 years. No female was found to be above the age group of 40 years. This could be the reason that we found a significant number of people with healthy periodontium as periodontitis is directly related to the increasing age (15).

We observed that brushing was the most common method for tooth cleaning among police personnel and these findings are in line with the study conducted in Pakistan(16). Along with brushing, miswak was also commonly used. Mouth rinsing with water was a common practice after the meal and $47 \%$ of the individuals brushes twice a day. Studies conducted in India expressed that most of the police personnel use toothbrush and brush at least once daily(17).

In this study, we established that more than half of the police personnel were suffering from gingivitis or periodontitis(18, 19). These issues need special attention, as they are associated with other systemic diseases. The values are barely distinguishable from a previous study conducted in Pakistan on a low-rank uniform army (20). Moreover, results of a hospitalbased study conducted in Karachi are in agreement with the findings of the current study (12). Furthermore, studies in India on police personnel are in accordance with the results of the current study (21, 22). Furthermore, we analyzed that periodontitis was more prevalent in older age individuals and males. These findings are concurring well with previous reports (23-25).

In the current study, we observed that female police personnel oral health was better than males. Studies have reported that females are more conscious about their oral health and practice better oral health. These findings are in agreement with the output of other studies $(26,27)$. 
Dental caries was highly prevalent among the police personnel and these values correlate favourably with a study conducted in India (28) which reported that 84.8 $\%$ of the police personnel having dental caries moreover our results share several similarities with the previous study conducted in Pakistan concluded that more than $70 \%$ of the adults have caries (29).

Only $12.1 \%$ of the subject visited the dentist in the last year and this finding is very low. The majority of the participants don't bother to visit the dentist. Around $21 \%$ males and $19 \%$ of the females never visited the dentist in their life and more than $45 \%$ males and $47 \%$ females visited dentists just once in the last five or more years, several studies conducted in Pakistan reported that even knowing the oral problems, patient delays and skipped their visits to dentists (30-32). Lack of awareness, low socioeconomic status, anxiety, fear, uneasy access, myths, etc. are the reasons reported in different studies $(33,34)$ The findings of our study are also in agreement with the study conducted in India (35). Studies have reported that policing is a stressful job (36) and it may also result in delaying visits to the dentists.

A previous survey conducted in Pakistan reported that $90 \%$ of all teeth affected with caries are not addressed properly and they remain untreated and one-third population required dental scaling (13). In agreement with these findings, our study observed that only 27 participants had healthy teeth and gingiva, and no treatment or intervention was required. Around 147 participants need thorough checkups along with dental scaling. The need for scaling and root planning $(84.48 \% \%)$ showed a greater similarity to the results of a study conducted in Shimla (26). Filling or root canal was suspected in 145 individuals. We observed that a large number of participants had mobile teeth, but extraction was advised to 45 police personnel due to grossly carious teeth and grade 2 or 3 mobility. We explored that 97 participants required or they will need prosthesis after extraction. The findings of our study are in agreement with a study conducted in India (35).

Due to the tedious and demanding job nature along with physical and psychological stress, it is very difficult to carry on normal routines of life. Police personnel due to their tough schedule and hard duty timings often overlook their very important task of daily life(37).

Dental pain even of a very small nature is enough to disturb sleep, increase stress, change mindset and concentration and may result in the disruption of the normal routine, so the proper oral and dental health of police personnel is not only important for their proficient performance but also for maintaining law and order situations and security for the entire community (38).

\section{Conclusion}

Police personnel have a compromised oral health status. Better oral health will not only prevent other systemic diseases but also boost and enhance their performance and decrease the number of absences due to any emergency dental issues or visits to the dentist. Regular dental screening should be mandatory and programs on oral health care and safety should be organized.

\section{Limitations:}

Despite this, we believe our work will be a starting point for further investigation and studies regarding oral and dental health in the police personnel of Pakistan the current study has some limitations. The small sample size and all the participants were from the SSU of Sindh Police based in Karachi. Limited resources and a lack of radiographic facilities. It is plausible that some limitations could have influenced the results obtained.

\section{Conflict of Interest:}

None

Funding:

None

\section{Acknowledgement:}

We are indebted and particularly grateful to the police personnel of the Special Security Unit of Sindh Police. We gratefully acknowledge the support of ethics and the review committee of Altamash Institute of Dental Medicine and we would also like to thank the students and house officers of Altamash Institute of Dental Medicine.

\section{References}

1. Park K. Chapter 2: Concept of Health and Disease. 20th ed: Banarsidas Bhanot, Jabalpur; 2009. 12-48 p.

2. Mahima V, Anudeep R, Karthikeya P. Mouth is the mirror of human body-diabetes mellitus and oral cavity. Clin Cases Invest. 2010;1(2):5-12.

3. Kudo Y, John MT, Saito Y, Sur S, Furuyama C, Tsukasaki $\mathrm{H}$, et al. Oral health in the Japan self-defense 
forces-a representative survey. BMC oral health. 2011;11(1):14.

4. Satapathy D, Behera T, Tripathy R. Health status of traffic police personnel in Brahmapur city. Indian journal of community medicine: official publication of Indian Association of Preventive Social Medicine. 2009;34(1):71.

5. Parsons JR. Occupational Health and Safety Issues of Police Officers in Canada, the United States and Europe: A Review Essay: Memorial University of Newfoundland Newfoundland; 2004 [Available from: https://www.mun.ca/safetynet/library/OHandS/Occ upationalHS.pdf.

6. Lynch J. Burnout and engagement in probationary police officers: A scoping paper: Australasian Centre for Policing Research; 2007.

7. Liberman AM, Best SR, Metzler TJ, Fagan JA, Weiss DS, Marmar CR. Routine occupational stress and psychological distress in police. Policing: An International Journal of Police Strategies \& Management. 2002.

8. Saha A, Sahu S, Paul G. Evaluation of cardio-vascular risk factor in police officers. International Journal of Pharma and Bio Sciences. 2010;1(4):263-71.

9. Liberman AM, Best SR, Metzler TJ, Fagan JA, Weiss DS, Marmar CR. Routine occupational stress and psychological distress in police. Policing: An International Journal of Police Strategies Management. 2002.

10. Linden GJ, Mullally BH, Freeman R. Stress and the progression of periodontal disease. Journal of clinical periodontology. 1996;23(7):675-80.

11. Babar Z, Chaudhry MP, Akhtar F. Frequency of chronic periodontitis in a cross section of Pak Army Personnel. Pakistan Armed Forces Medical Journal. 2008;58(2):1858.

12. Siddiqui TM, Wali A, Siddiqui SH, Heyat U, Nadeem M, Shamim M. An Epidemiological Study of Prevalence of Dental Caries and Periodontal Disease among Adults in Deprived Areas-Karachi. JOHR. 2013;4(1):3-7.

13. Khan AA, Sharea I, Ayma S, Ambreena Q, Inayatullah P, Sofia S. Oral health in Pakistan: a situation analysis. Dev Dent. 2004;5(2):35-44.

14. Organization WH. Oral Health Assessment Form for Adults, 2013 [Available from: https://www.who.int/oral_health/publications/pepan nex1formadulttooth.pdf?ua=1.

15. Slots J, Feik D, Rams TE, immunology. Age and sex relationships of superinfecting microorganisms in periodontitis patients. Oral microbiology. 1990;5(6):3058.

16. Ali S, Ijaz S. ORAL HEALTH. The Professional Medical Journal. 2014;21(02):343-6.

17. Singh A, Bhambal A, Saxena S, Tiwari V, Tiwari U, Shrivastava R. Oral hygiene practices and its relationship with periodontal status among police personnel of Bhopal city, Central India: An epidemiological study. CHRISMED Journal of Health and Research. 2015;2(4):342.

18. Tonetti MS, Van Dyke TE, workshop* wgotjEA. Periodontitis and atherosclerotic cardiovascular disease: consensus report of the Joint EFP/AAPWorkshop on Periodontitis and Systemic Diseases. Journal of periodontology. 2013;84:S24-S9.

19. Winning L, Linden GJ. Periodontitis and systemic disease: association or causality? Current oral health reports. 2017;4(1):1-7.

20. Chaudhry MP BZ, Akhtar F. 2003;53:26-8. Current status of periodontal disease in the junior ranks of Army Units at Rawalpindi. Pak Armed Forces Med J. 2003;53:26-8.

21. Sohi R, Bansal V, Veeresha K, Gambhir RJTIJoE. Assessment of oral health status and treatment needs of police personnel of Haryana, India. 2010;9(1).

22. Basavraj P, Khuller N, Kumar PJJIAPHD. Dental caries experience and periodontal status of police personnel in Ghaziabad city. 2011;17:44-8.

23. Leite FR, Nascimento GG, Scheutz F, Lopez R. Effect of smoking on periodontitis: a systematic review and meta-regression. American Journal of Preventive Medicine. 2018;54(6):831-41.

24. Karasneh JA, Al Habashneh RA, Marzouka NAS, Thornhill MH. Effect of cigarette smoking on subgingival bacteria in healthy subjects and patients with chronic periodontitis. BMC oral health. 2017;17(1):64.

25. Carasol M, Llodra JC, Fernández-Meseguer A, Bravo M, García-Margallo MT, Calvo-Bonacho E, et al. Periodontal conditions among employed adults in Spain. Journal of clinical periodontology. 2016;43(7):54856.

26. Bhardwaj V, Sharma K, Veeresha K. Periodontal status and treatment needs among state government employees in Shimla city, Himachal Pradesh (India): A cross-sectional study. Indian Journal of Oral Sciences. 2012;3(1):28-.

27. Halboub ES, Al-Maweri SA, Al-Jamaei AA, Al-Wesabi MA, Shamala A, Al-Kamel A, et al. Self-reported oral health attitudes and behavior of dental and medical students, Yemen. Glob J Health Sci. 2016;8(10):56676.

28. Bali R, Mathur V, Talwar P, Chanana H. National oral health survey and fluoride mapping 2002-2003 India. New Delhi: Dental Council of India. 2004;132.

29. Maher R. Dental disorders in Pakistan--a national pathfinder study. Pak Med Assoc. 1991;41(10):250-2.

30. Saleem Z, Abbas SA, Nadeem F, Majeed MM. The habits and reasons of delayed presentation of patients with oral cancer at a tertiary care hospital of a third world country. Pakistan Journal of Public Health. 2018;8(3):165-9.

31. Dawani N, Afaq A, Bilal S. Oral Health Knowledge, Attitude and Practices Amongst Teachers of Public 
School Set-up of Karach, Pakistan. Journal of the Dow University of Health Sciences. 2013;7(1):15-9.

32. Fatima SH, Naseem S, Awan SA, Ghazanfar H, Ali Z, Khan NA. Oral Health Practices Among Pakistani Physicians. Cureus. 2018;10(1).

33. Zarah S MM, Imtiaz A. Dental Anxiety among the Students of Public Sector Medical Universities of Karachi. J Dent Oro Surg. 2016;1(2):111.

34. Mirza BAQ, Ahmad F, Saleem MN. Dental Caries Experience and Use of Dental Services among Female Students of Garrison School. JPDA. 2017;26(01):11.

35. Bhalla $M$, Ingle NA, Kaur N, Ingle E, Chandan D, Charania Z. Oral health status and treatment needs of police personnel in Mathura city. Journal of international oral health: JIOH. 2015;7(9):51.
36. Masilamani R, Bulgiba A, Chinna K, Darus A, Isahak M, Kandiben $S$, et al. Prevalence and associated factors of stress in the Malaysian Police Force. Preventive medicine. 2013;57:S57-S9.

37. Dilip C. Health status, treatment requirements, knowledge and attitude towards oral health of police recruits in Karnataka. Journal of Indian Association of Public Health Dentistry. 2005;5(5):20.

38. Sutthavong S, Cae-Ngow S, Rangsin R. Oral health survey of military personnel in the Phramongkutklao Hospital, Thailand. Journal of the Medical Association of Thailand= Chotmaihet Thangphaet. 2009;92:S84-90. 